\title{
Land-Sea Interactions and the Ecosystem Approach in Ocean Planning and Governance
}

\author{
Sue Kidd
}

\section{Introduction}

When contemplating planning and governance of human development it is perhaps typical to focus attention on the land. However, as this volume demonstrates it is also important to remember that the sea covers more than two thirds of our planet's surface and provides a wide range of essential goods and services upon which humans, and ultimately all life on Earth, depend. Indeed, land-sea interactions (LSI) have been significant in shaping patterns of human activity on both land and sea since ancient times. For example, humans have always looked to the sea for food, transport and trade, waste disposal and cultural and spiritual fulfilment, and coastal areas have been favoured places for human settlement. Today 16 of the world's 23 mega cities (with populations exceeding 10 million) are in coastal locations ${ }^{1}$ and with the prospect of the global population rising from 7.6 billion in 2017 to over 11 billion by $2100^{2}$ ongoing urbanisation of coastal areas can be anticipated. Beyond general trends of globalisation and the importance of international connectivity, one of the factors driving contemporary coastal and marine development is that the sea is increasingly being seen as a source of new 'Blue Growth' opportunities. Established maritime sectors, such as shipping and offshore oil and gas production, are now frequently accompanied by a range of other offshore uses, such as aquaculture and wind power developments. Technological advances are also opening new business possibilities in sectors such as blue biotechnology, ocean renewable energy and marine mineral extraction ${ }^{3}$. Alongside these very tangible human interactions with the marine environment, modern science is revealing the reality of less tangible, but in many ways more profound

1 M Pelling and S Blackburn, Megacities and the coast: risk, resilience and transformation (Routledge 2014).

2 United Nations World, Population Prospects: The 2017 Revision (United Nations 2017).

3 Ecorys, Blue Growth: Scenarios and drivers for Sustainable Growth from the Oceans, Seas and Coasts: Final Report (European Commission, Directorate General for Maritime Affairs and Fisheries 2012).

(C) SUE KIDD, 2019 | DOI:10.1163/9789004389984_006

This is an open access chapter distributed under the terms of the prevailing CC-BY-NC License at the time of publication. 
dependencies on the sea, including the vital role it plays in climate regulation and carbon capture. Equally, it is enhancing our understanding of the intricate web of connections between human activity - both land and sea based - and the health of the marine environment.

It is within this context that a new era of ocean planning and governance is emerging. This is reflected most notably in the creation of new systems of Marine Spatial Planning (MSP) across the world. By 2017 it was estimated that over 60 countries had some form of MSP process in place, ${ }^{4}$ each addressing issues related to land-sea interactions in different ways reflecting variations in physical and human geography, administrative and legislative histories, and cultural norms and practices. However, there is also a shared context at play linked to international conventions including the Convention of Biological Diversity (СвD), the United Nations Convention on the Law of the Sea (Law of the Sea Convention or LOSC), and a range of regional seas conventions. Prominent here is a requirement for the new systems of ocean planning and governance, including those related to MSP, to adopt the Ecosystem Approach (EA). ${ }^{5}$ What the EA means for evolving ocean planning and governance arrangements is a subject of much interest and debate as illustrated by the contributions gathered together in this volume. The subject of this chapter is an important strand within the debate. It relates to the connection between LSI and the evolving EA-informed ocean planning and governance arrangements, and what this connection might mean for landward communities and governance of the land.

This chapter starts by outlining a general framework for considering land-sea interactions (LSI) in ocean governance. It then revisits the EA principles and teases out their natural and social science dimensions before exploring some of the LSI issues raised in their application in ocean planning and governance from these different perspectives. In these discussions particular reference is made to experience in Europe, where the 2014 EU Maritime Spatial Planning Directive is prompting the rapid development of ocean governance arrangements informed by specific consideration of both EA and land sea interactions. ${ }^{6}$

4 Charles Ehler, Final Report of 2nd International Conference on Marine/Maritime Spatial Planning (Intergovernmental Oceanographic Commission-United Nations Educational, Social and Cultural Organisation-unEsco, European Commission-Directorate General for Maritime Affairs and Fisheries 2018).

5 Sue Kidd, Andy Plater and Chris Frid, The Ecosystem Approach to Marine Planning and Management (Routledge 2011).

6 European MsP Platform, Maritime Spatial Planning: Addressing Land-Sea Interaction St. Julian's Malta, 15-16 June 2017 Conference Report (European Commission, Directorate General for Maritime Affairs and Fisheries 2017). 
The chapter concludes with some reflections on the implications of the analysis for the future of ocean governance and argues that efforts to develop a Blue Society should be supported, and that a new era of territorial planning and governance covering both the land and the ocean is in prospect and to be welcomed.

\section{A General Framework for Considering Land-Sea Interactions in Ocean Governance}

LSI is a complex phenomenon, involving both natural processes across the land-sea interface and the interrelationships between human activities in this zone. Many of the issues of concern for ocean governance are closely related to LSI. Figure 5.1 presents a general framework for considering LSI that has been developed to inform the emerging MSP arrangements in the European Union. This framework is also felt to be helpful in exploring LSI issues in ocean governance more generally.

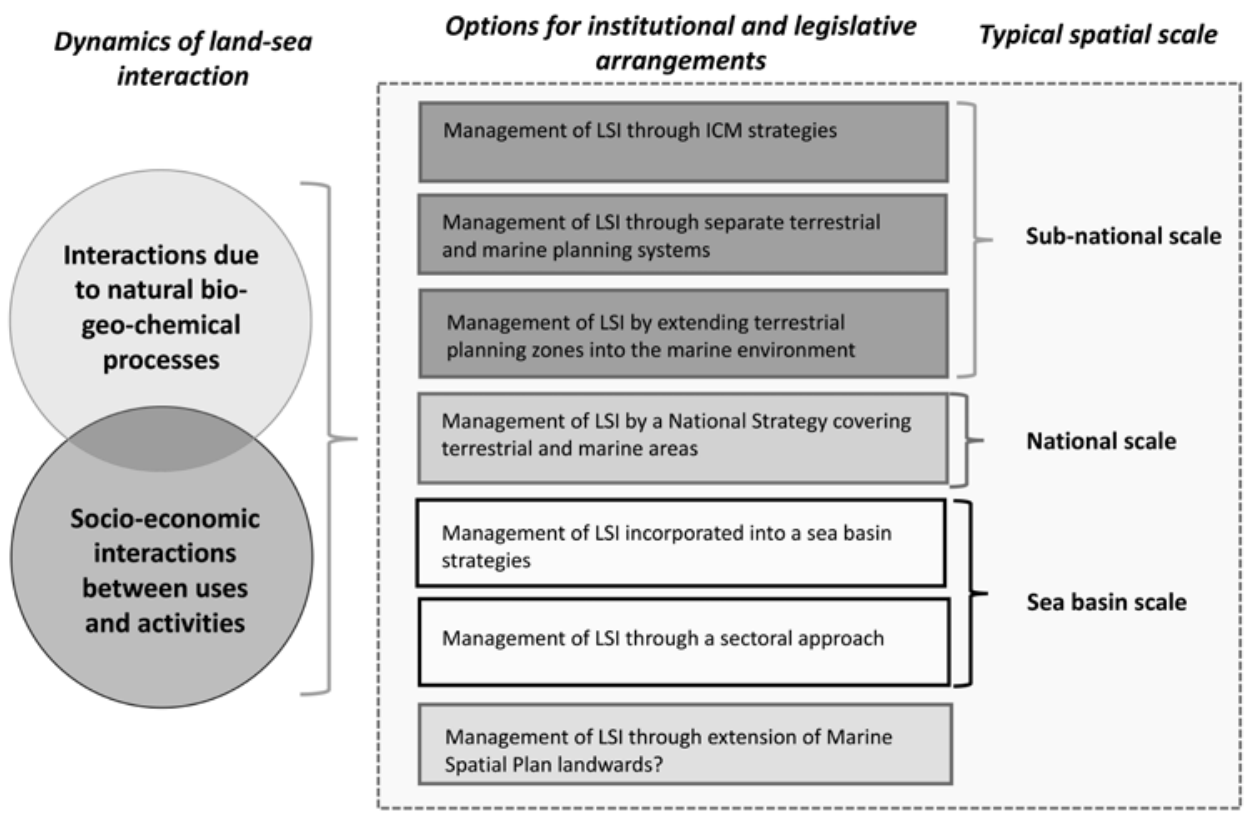

FIGURE 5.1 A General Framework for Addressing Land-Sea Interaction Note: European MSP Platform (n 6) 
The framework illustrates that interactions between the land and sea include those driven by natural bio-geo-chemical processes, such as agricultural runoff resulting in eutrophication of coastal waters. ${ }^{7}$ Although developments close to the coast are likely to have the most direct natural process interactions, it should be recognised that development even very distant from the coast can impact ocean ecology, for example by polluting rivers which discharge into the sea or by being the source of atmospheric pollution including that associated with climate change which ultimately finds its way into the ocean. Indeed, human induced climate change arising most significantly from landward activity poses some of the greatest threats to the good environmental status of the marine environment through ocean warming and ocean acidification. These processes impact marine life and have the potential to affect the ocean's critical role in carbon capture and global climate amelioration.

A number of European Union funded projects and national studies have sought to investigate natural process related LSI interactions and their impact on the marine environment and to examine and develop best practices and guidelines which can be used by those involved in ocean governance to manage LSI. Examples include work undertaken for the Danish National Environmental Research Institute ${ }^{8}$ and as part of the Celtic Seas Partnership project. ${ }^{9}$

Figure 5.1 illustrates that there are also important LSI between socio-economic activities. For example, many maritime uses need support installations on land, while some uses existing mostly on land (e.g., tourism, recreation, and ports) expand their activities into the sea as well. These interactions need to be understood as part of ocean governance activities, in order to assess and address their individual and cumulative impacts and potential conflicts and synergies.

Such interactions have also been studied on national and regional scales by national governments and by European Union funded projects. European Seas Territorial Development Opportunities and Risks (ESTaDOR) was one such project which formed part of the European Spatial Observation Network (ESPON) 2013 programme. ESTaDOR sought to explore both the development opportunities and risks for Europe's maritime regions by understanding landsea interactions as an integrated whole. The project created a typology map of European Seas and associated inland areas demonstrating (through analysis

7 A Monaco and P Prouzet, The Land Sea Interactions (Wiley and Sons Incorporated 2016).

8 G Ærtebjerg, JH Andersen and OS Hansen (eds), Nutrients and Eutrophication in Danish Marine Waters. A Challenge for Science and Management (Danish National Environmental Research Institute 2003).

9 University of Liverpool, Marine Proofing for Good Environmental Status of the Sea: Good Practice Guidelines for Terrestrial Planning (Celtic Seas Partnership 2016). 
of data related to transport flows, the socio-economic significance of the maritime economy and environmental pressures) where land-sea interactions are at their most intense. ${ }^{10}$ The study revealed that the English Channel and southern North Sea was the core region in Europe from an LSI perspective due to the concentration of population and economic activity on the London, Paris, Amsterdam axis, the presence of mega-ports such as Rotterdam, and channels such as the Nord-Ostsee-Kanal, one of the main trade routes between Europe and the rest of the world. Regional hubs, for example in the UK, Ireland and northern France, were equally evident in showing strong land-sea interactions and playing host to important maritime industry clusters. The study was also important in highlighting more rural and wilderness areas where LSI were much less intense.

Alongside bio-geo-chemical processes and socio-economic interrelationships associated with the dynamics of LSI, the framework set out in Figure 5.1 outlines a range of options for institutional and legislative arrangements to address LSI. The examples provided are drawn from reflections on the European ocean governance experience. ${ }^{11}$ This reveals that LSI interactions may be managed through Integrated Coastal Management (ICM) initiatives. For example, Croatia is developing a Joint Management Strategy for Marine Environmental and Coastal Zone Areas and a related action programme. Alternatively, some European countries have chosen to maintain separate terrestrial and marine planning systems whilst still ensuring land-sea interactions are taken into consideration. Examples of this can be seen in Finland and in the UK. There are also countries which have extended the remit of local and regional scale territorial plans into the marine environment with a view to addressing land-sea interactions. For example, spatial planning in the Mecklenburg-Vorpommern länder in Germany covers land and sea areas out to $12 \mathrm{~nm}$. Another approach is to manage LSI through the creation of a single national strategy which encompasses both the terrestrial and the marine environment. This approach has been taken by the Netherlands and Malta. Management of LSI can also be undertaken on a larger, sea basin scale. For example, in the Baltic Sea Region, Vision and Strategies around the Baltic Sea (VASAB) was established as an intergovernmental multilateral co-operation to develop long-term strategies and visions for the region, including spatial planning and

10 University of Liverpool, ESTaDOR European Seas Territorial Development Opportunities and Risks: Executive Summary (European Spatial Planning Observation Network 2013).

11 European MSP Platform, Maritime Spatial Planning: Addressing Land-Sea Interaction St. Julian's Malta, 15-16 June 2017 Conference Report (European Commission, Directorate General for Maritime Affairs and Fisheries 2017). 
development of both land and sea areas. In the Mediterranean, the United Nations Environment Programme's Mediterranean Action Programme is taking LSI on board. Examples of LSI being managed within sectors themselves are also evident. These include the European Union funded co-EvoLve project which is analysing and promoting the co-evolution of human activities and natural systems in coastal tourism areas in the Mediterranean, allowing for the sustainable development of tourist activities based on the principles of ICM and MSP. Figure 5.1 finally indicates that it is technically possible that LSI could be addressed by extending the remit of MSP inland. However, this is not an approach that appears to have been adopted in Europe or elsewhere so far.

What is evident from the above examples is that LSI can be addressed in a variety of ways and at a variety of scales of governance. These include:

- Local areas, such as ICM partnerships and economically-driven initiatives, involving municipalities and other local interests;

- Sub-national planning territories, such as maritime plan areas, involving MSP authorities working in collaboration with coastal authorities and maritime stakeholders;

- National territories, where a national strategy or plan, covering the whole of the nation's waters, and possibly its land area as well, may guide LSI efforts;

- Sea-basins / transnational regions, where transnational cooperation may produce a strategy or protocol for guiding national LSI efforts and ensuring ongoing cross-border cooperation.

These scales are not mutually exclusive. For example, there are cases where sea-basin strategies are being implemented or supplemented at a sub-national or local level through other instruments for addressing LSI.

\section{3}

\section{The EA Revisited}

The previous section outlined a framework to consider the dynamics of LSI and different options for institutional and legislative arrangements that are emerging to address LSI in ocean governance practice in Europe. It is important to note that in line with $\mathrm{CBD}$ and LOSC commitments this European practice is developing with the EA very much in mind. In the following sections the connections between the EA, LSI and ocean governance arrangements are considered further. In order to set the scene for this discussion it is helpful to go back to the definition of the EA and subsequent development of EA principles by the Conference of the Parties (COP) to the CBD. 
Through Decision $2000 \mathrm{v} / 6$, the cop defined the EA as:

A Strategy for the integrated management of land, water, and living resources which promotes conservation and sustainable use in an equitable way.

This decision also emphasised the integrated management practices that follow the EA should be focussed upon:

levels of biological organisation, which encompass essential structure, processes, functions and interactions among organisms and their environment (...) recogniz(ing) that humans, with their cultural diversity are an integral component of many ecosystems.

Underpinning this definition, the COP has developed a series of 12 complementary and interlinked EA principles to provide additional guidance to those involved in applying EA to their activities (see Table 5.1).

TABLE 5.1 Convention on Biological Diversity: Ecosystem Approach Principles ${ }^{\mathrm{a}}$

1. The objectives of management of land, water and living resources are a matter of societal choice.

2. Management should be decentralized to the lowest appropriate level.

3. Ecosystem managers should consider the effects (actual or potential) of their activities on adjacent and other ecosystems.

4. Recognizing potential gains from management, there is usually a need to understand and manage the ecosystem in an economic context. Any such ecosystem-management programme should:

(a) Reduce those market distortions that adversely affect biological diversity;

(b) Align incentives to promote biodiversity conservation and sustainable use;

(c) Internalize costs and benefits in the given ecosystem to the extent feasible.

5. Conservation of ecosystem structure and functioning, in order to maintain ecosystem services, should be a priority target of the ecosystem approach.

6. Ecosystems must be managed within the limits of their functioning.

7. The ecosystem approach should be undertaken at the appropriate spatial and temporal scales.

8. Recognizing the varying temporal scales and lag-effects that characterize ecosystem processes, objectives for ecosystem management should be set for the long term.

9. Management must recognize that change is inevitable. 
TABLE 5.1 Convention on Biological Diversity: Ecosystem Approach Principles (cont.)

10. The ecosystem approach should seek the appropriate balance between, and integration of, conservation and use of biological diversity.

11. The ecosystem approach should consider all forms of relevant information, including scientific and indigenous and local knowledge, innovations and practices.

12. The ecosystem approach should involve all relevant sectors of society and scientific disciplines.

a CBD Conference of the Parties, $2000 \mathrm{~V} / 6$

The overarching concern of the EA is the development of integrated institutional and legislative arrangements for land, water, and living resources which, by following EA principles, promote conservation and sustainable use in an equitable way. As Figure 5.2 illustrates, the EA principles interweave natural science understanding related to natural bio-geo-chemical process with social science understanding related to socio-economic processes. Figure 5.2 also illustrates the convergence of core messages from these differing knowledge bases including a common recognition of system complexity and associated uncertainty and the consequent merits of democratic debate and adaptive management practices accepting that change is inherent and inevitable. Interestingly, consideration of LSI seems to present a particularly relevant lens through which to explore the implications of the EA principles in ocean as well as terrestrial governance contexts. Interactions

EA Principle 3 - requiring managers to consider the effects (actual or potential) of their activities on adjacent and other ecosystems, EA Principle 5- emphasising the need to conserve ecosystem structure and functioning in order to maintain ecosystems services, and EA Principle 7 - requiring planning and management to operate at appropriate spatial and temporal scales, are a good place to start when considering LSI from a natural science perspective.

In relation to EA Principle 3 it must be acknowledged that terrestrial and marine ecosystems are not just adjacent to each other but are closely interlinked. Indeed many (if not most) pressures on the marine environment of concern for ocean governance are landward in origin and are connected to 
The Ecosystem Approach \& Ocean Governance Land-Sea Interactions

\begin{tabular}{|c|c|}
\hline Natural Science & Social Science \\
\hline $\begin{array}{l}\text { EA Principle 3: Consider the } \\
\text { extended impacts, or externalities. }\end{array}$ & $\begin{array}{l}\text { EA Principle 1: Recognise objectives } \\
\text { as society's choice. }\end{array}$ \\
\hline $\begin{array}{l}\text { EA Principle } 5 \text { : Prioritise } \\
\text { ecosystem services }\end{array}$ & $\begin{array}{l}\text { EA Principle 2: Aim for decentralised } \\
\text { management (i.e. subsidiarity). }\end{array}$ \\
\hline $\begin{array}{l}\text { EA Principle 6: Recognise and } \\
\text { respect ecosystem limits. }\end{array}$ & $\begin{array}{l}\text { EA Principle 4: Understand the } \\
\text { economic context and aim to reduce } \\
\text { market distortion. }\end{array}$ \\
\hline $\begin{array}{l}\text { EA Principle 7: Operate at an } \\
\text { approprite scale, spatiali and } \\
\text { temporally }\end{array}$ & $\begin{array}{l}\text { EA Principle 10: Balance use and } \\
\text { preservation. }\end{array}$ \\
\hline \multirow[t]{2}{*}{$\begin{array}{l}\text { EA Principle 8: Manage for the } \\
\text { long term, considering lagged effects. }\end{array}$} & $\begin{array}{l}\text { EA Principle 11: Bring all knowledge to } \\
\text { bear. }\end{array}$ \\
\hline & $\begin{array}{l}\text { EA Principle 12: Involve all relevant } \\
\text { stakeholders }\end{array}$ \\
\hline
\end{tabular}

FIGURE 5.2 Overview of Natural and Social Science Perspectives and the Ecosystem Approach

Note: Developed by the author

wider human development trends and aspirations. In terms of EA Principle 5 it is also evident that landward development has the potential to impact in a negative way on the structure and functioning of the marine environment and in so doing to put at risk the important supporting, regulating, provisioning and cultural services that humans as well as other life forms derived from the sea. ${ }^{12}$ In the context of EA Principle 7 , the mainly landward origins and significant marine impacts of climate change are perhaps the most persuasive examples of where planning and management of human activities on land are critical to addressing what might be regarded as the key ocean governance issue of the present time. Principle 7 also highlights that concerted and sustained action at multiple scales is needed if climate change is to be addressed in an appropriate manner.

12 Swedish Environmental Protection Agency, What's in the sea for me? - Ecosystem Services Provided by the Baltic Sea and Skagerrak (Swedish Environmental Protection Agency 2009). 
The challenges associated with this situation are quite daunting as they indicate the need not only for improved natural science understanding of LSI but also of related ocean literacy among key sea and land decision makers if EA principle 6 - advocating that (ocean) ecosystems must be managed within the limits of their functioning, and EA Principle 8 - recognizing the varying temporal scales and lag-effects that characterise ecosystem processes require objectives for ecosystem management to be set for the long term, are to be addressed.

\section{Social Science Perspectives within the EA and Land-Sea} Interactions

There are clearly immense societal challenges inherent in LSI and the EA that need to be addressed by those engaged in ocean, and also terrestrial, governance. It is therefore not surprising that, as Figure 5.2 indicates, many of the EA principles developed by the COP are social science in their orientation. These include EA Principle 1 - the objectives of management of land, water and living resources are a matter for societal choice; EA Principle 2 - advocating decentralising management to the lowest possible level; EA Principle 11 - relating to consideration of all forms of relevant information, including scientific and indigenous and local knowledge; and EA principle 12 - requiring the involvement of all relevant sectors of society and scientific disciplines.

The call for wide and meaningful stakeholder engagement is a common thread running through these EA principles. From an ocean governance perspective this raises again the need for widespread ocean literacy but also suggests something arguably deeper, perhaps reflected in the developing notion of a Blue Society, which is discussed further below. For example, to apply EA Principle 1 in relation to ocean governance, it seems essential that there are basic levels of societal knowledge about the sea and LSI issues. However, it also suggests there should be meaningful opportunities for public/democratic debate about decisions that might impinge upon the future wellbeing of the oceans, whether they are taken by land orientated organisations or those with a specific ocean focus. EA Principle 2 arguably goes further in advocating decentralised approaches to management and active engagement of communities in local maritime stewardship. It is therefore important to note that, to date, ocean governance arrangements have tended to be mainly national or international in scale, although as we have seen in places LSI issues have spawned local ICM initiatives. Interestingly, these often demonstrate a commitment to involving all parties concerned, including economic and social partners, local residents, 
business organisations and NGOS, in local management activities, ${ }^{13}$ and are successful in attracting strong community support and input. In this sense ICM initiatives might provide exemplars for wider ocean governance practice not only in relation to EA Principle 2 but also for EA Principles 11 and 12.

In reflecting upon the EA principles from an LSI perspective, Principle 9 management must recognize that change is inevitable - stands out as being of particular significance. Even from the most simplistic viewpoint, it is obvious that management of change is of central concern to ocean governance as the sea is a highly dynamic and changing environment. Not only is this reflected in bio-geo-chemical processes but also in human activities associated with the sea, which often follow daily, monthly, and seasonal fluctuations and respond to natural processes that are constantly reshaping the land-sea interface. Moreover, Principle 9 is useful in drawing attention to the pace of change in the marine environment. This was brought into sharp focus by the United Nations' Millennium Ecosystem Assessment, which concluded that marine and coastal ecosystems are being degraded and used unsustainably and are deteriorating faster than other ecosystems. ${ }^{14}$ Notably in the context of this chapter, it found that the major drivers of change, degradation, or loss of marine and coastal ecosystems and services are mainly anthropogenic. These include key LSI related issues including: population growth; land use change and habitat loss; climate change; eutrophication; pollution; technology change; globalization; increased demand for food; and a shift in food preferences. A key message to emerge from the Millennium Ecosystem Assessment was that the highly threatened nature of marine and coastal ecosystems demands a local, regional, and global response. Reflecting on the analysis presented in this chapter, it is evident that this response must not simply look to the ocean but must also look to the land and bring in a new era of governance connectivity across the land-sea divide. An interesting interpretation of EA Principle 9 is that change in our governance structures is in itself perhaps inevitable and some thoughts

13 B Cicin-Sain and others, Integrated coastal and ocean management: concepts and practices (Island Press 1998); Ruprecht Consult and The International Ocean Institute, Evaluation of Integrated Coastal Zone Management in Europe: Final Report (European Commission 2006).

14 United Nations Environment Programme, Marine and coastal ecosystems and human wellbeing: A synthesis report based on the findings of the Millennium Ecosystem Assessment (UNEP 2006). 
about what these changes might entail from an EA and LSI informed perspective are outlined below.

\section{Improving Governance through Ocean Literacy}

Before setting out some thoughts for the future a brief recap of key messages from the preceding discussions is provided. First, it is evident that we are entering a period of considerable innovation and development in ocean governance, not least in the emergence of new systems of MSP in coastal countries all over the world. Although a diversity of approaches is apparent reflecting different country contexts, in line with international agreements such as the CBD and LOSC the EA is providing a common reference point in these developments. The EA promotes the integrated management of land, water and living resources and, as we have seen, application of EA principles to LSI related issues raises some intriguing questions not only for future patterns of ocean governance but for governance more generally. Examination of the dynamics of land-sea interactions reveals the complex interweaving of bio-geo-chemical processes and social economic activities across the land-sea interface and highlights the landward origin of many issues that are of central concern for ocean governance. As a consequence, how to address LSI in an effective way has been an important issue influencing the recent evolution of ocean governance arrangements. A number of different approaches can be identified ranging from localised ICM initiatives to integrated sea-basin strategies, all of which connect in some way to EA ambitions regarding integrated management. Indeed, it is encouraging to see, certainly in Europe, the level of attention that is being given to EA and LSI in evolving institutional and legislative arrangements related to planning for marine areas. However, while there is much useful experience to reflect upon and to guide others in their efforts, close examination of EA principles highlights significant ocean governance related challenges. In particular, it is evident that a transformation is needed in society's relationship with the ocean and in wider patterns of governance if EA ambitions are to be addressed. With this in mind, some thoughts on the development of a Blue Society and an associated new era of 'territorial' (land/ sea) governance are set out.

\subsection{Land Sea Interactions and Ocean Literacy for a Blue Society}

As we have seen, wide and meaningful engagement is a central idea within the EA (reflected in particular in EA principles 1, 2, 11 and 12). Its significance in relation to ocean governance is brought into focus in considering LSI issues 
where it is apparent that landward as well as seaward action is required to minimise adverse effects of human development on the marine environment and realise opportunities and beneficial synergies related to maritime activities. However, basic levels of understanding are needed for wide and meaningful engagement to take place and for society to exercise informed choices regarding activities that impinge on the health of the marine environment. It is therefore not surprising that the need for wider ocean literacy is reflected in the Call for Action that emerged from the United Nations' Oceans Conference, held in New York in June 2017, to support the implementation of United Nations' Sustainable Development Goal 14: 'Conserve and sustainably use the oceans, seas and marine resources for sustainable development'.15 The Call for Action encourages the development of ocean-related education in order to promote ocean literacy and a culture of conservation, restoration and sustainable use of the ocean.

Ocean literacy has been the subject of much discussion in the USA and elsewhere since the mid-199os as a result of growing collaboration between natural scientists and educators. ${ }^{16}$ Activities associated with the USA based Ocean Literacy Campaign for example have led to the identification of seven natural science informed principles of ocean literacy (See Table 5.2) which, it is suggested, everyone should understand about the ocean. These principles capture core ideas about the nature of ocean ecosystems and their connections to the wider Earth System and provide a strong foundation for ocean literacy activity. However, clearly more is needed to enable society to engage with and respond to the ocean issues discussed above, including those related to LSI.

A second area of understanding that seems to be critical to ocean literacy relates to managing human interaction with the sea. This includes knowledge of: the anthropogenic drivers of change in the marine environment and associated pressures they cause; their impacts on ocean ecosystem functioning and consequent implications for the state of the health of the sea and wider Earth System; and the types of planning and management responses than can be put in place to reduce or mitigate adverse interactions and promote sustainable development. The widely used Driver-Pressure-State-Impact-Response (DSPIR) problem structuring framework (and refinements of this which are being developed particularly with marine environmental management

15 Intergovernmental Oceanographic Commission (of UNESCO), Outcomes of the UN SDG 14 conference (5-9 June 2017): Information Document, (Intergovernmental Oceanographic Commission, Paris, 2017).

16 S Schoedinger, LU Tran and L Whitley, 'From the Principles to the Scope and Sequence: A brief history of the ocean literacy campaign' (2010) Special Report 3 The Journal of Marine Education 3. 
TABLE 5.2 Ocean Literacy Principles ${ }^{\mathrm{a}}$

Ocean Literacy Principle 1: The Earth has one big ocean with many features.

Ocean Literacy Principle 2: The ocean and life in the ocean shape the features of Earth.

Ocean Literacy Principle 3: The ocean is a major influence on weather and climate.

Ocean Literacy Principle 4: The ocean made the Earth habitable.

Ocean Literacy Principle 5: The ocean supports a great diversity of life and ecosystems.

Ocean Literacy Principle 6: The ocean and humans are inextricably interconnected. Ocean Literacy Principle 7: The ocean is largely unexplored.

a Ocean Literacy Campaign, Ocean Literacy: The Essential Principles and Fundamental Concepts of Ocean Sciences for Learners of All Ages Version 2, a brochure resulting from the 2-week On-Line Workshop on Ocean Literacy through Science Standards (National Oceanic and Atmospheric Administration, USA, 2013).

in mind) could be useful in guiding this second element of ocean literacy understanding. ${ }^{17}$

From an EA and governance perspective, it can be argued that a third component of ocean literacy is also important. This relates to ocean citizenship and the legal framework for the ocean which, in significant ways, is quite distinct from that of the land. The reason for this is that together with the atmosphere, Antarctica and outer space, parts of the ocean, in particular the High Seas, are recognised as the world's global commons where the legal framework is founded on the principle of mare liberum (freedom of access and use for everyone). ${ }^{18}$ While today, the LOsC grants to coastal states sovereignty over their territorial sea out to 12 nautical miles and sovereign rights relating to the exploration and exploitation of natural resources within the water column of their Exclusive Economic Zone and on their Continental Shelf, the Convention also imposes responsibilities related to their conservation and management. Nevertheless, it is crucial to note that the role of the state is that of a trustee acting on behalf of its citizens (including future generations) who are the common property owners. ${ }^{19}$ In this sense, common ownership interests

17 N Schrijver, 'Managing the global commons: common good or common sink?' (2016) 37:7 Third World Quarterly 1252.

18 G Osherenko, 'New Discourses on Ocean Governance: Understanding Property Rights and the Public Trust' (2006) 21 Journal of Environmental Law and Litigation 317.

19 Ibid. 
apply in some way in all ocean areas and, as a consequence, a key aspect of ocean literacy should be to disseminate an understanding of the legal framework to landward communities and foster their role in ensuring good ocean governance through careful application of the rule of law, participation, transparency, consensus-based decision making, accountability, equitability and inclusiveness, responsiveness, and coherency. ${ }^{20}$

There is growing appreciation of the merits of a broad-based approach to ocean literacy and again EU funded projects provide examples of innovation in taking this forward. For example, the Sea Change project aims to establish a fundamental 'Sea Change' in the way European citizens view their relationship with the sea, by empowering them, as ocean literate citizens, to take direct and sustainable action towards a healthy ocean, healthy communities, and ultimately a healthy planet. The project defines an Ocean Literate person as someone who: understands the importance of the ocean to humankind; can communicate about the ocean in a meaningful way; and is able to make informed and responsible decisions regarding the ocean and its resources. ${ }^{21}$ The Sea for Society project considered similar themes but took a broader view in seeking to develop and enrich the concept of a 'Blue Society'. With a focus beyond the individual, Blue Society involves a vision in which people benefit from the Ocean's vast potential while preserving its environmental integrity. Central to this vision is the development of systems of governance in which the Ocean is recognised as a global common which must be collectively managed across sectors and borders. ${ }^{22}$ The project concluded that ocean related education had a key role to play in developing a Blue Society. It also emphasised the need for innovations to promote more integrated forms of governance, a theme returned to below.

\subsection{Land Sea Interactions and Innovations in 'Territorial' Governance}

As the Blue Society concept indicates, ocean literacy is concerned with promoting behavioural change not only at an individual level but also at a societal level. Here, it is apparent that in particular innovation in approaches to governance is needed to address the LSI issues outlined earlier and respond to EA ambitions for the integrated management of land, water, and living resources. It is therefore interesting to note that the introduction of new systems of MSP

20 YT Chang, Ocean Governance a Way Forward (Springer, 2012).

21 European Marine Board and CoExploration Limited, Sea Change Ocean Literacy Fact Sheet (European Marine Board and CoExploration, Limited, no date).

22 Societe d'exploitation Du Centre National de la Mer, Sea For Society: Final Report Summary (European Commission, Community Research and Information Development Service, 2013). 
is heralding an era of governance experimentation that is not simply ocean focussed but is also prompting change in established patterns of governance of the land. In Europe, various approaches have been identified which may point useful ways forward. Although it is as yet too early to undertake a detailed analysis of their relative merits in addressing LSI and/or delivering EA integrated management ambitions, some insight may be derived from the outputs of the European MSP Conference on Addressing Land Sea Interactions that took place in 2017. This included expert discussion on the relative strengths and challenges of different approaches from an LSI perspective and some of the key findings are presented below. ${ }^{23}$

In relation to LSI and ICM based governance approaches these were felt to have a number of important strengths including: having a strong foundation in well-founded ICM principles that reflect EA understanding; an established network of respected ICM initiatives upon which to build; a wide view of integration issues and (due to their mainly non statutory format and local focus) flexibility to integrate many different interests and address issues of particular importance in each local context. On the other hand, it was recognised that the voluntary or project-based format of most ICM initiatives to date made delivering concrete results difficult and that there was a wide variation in the experience of ICM with many gaps in geographical coverage. Perhaps most significantly though in the context of this chapter, it was noted that the local/ coastal focus of most ICM initiatives was not strategic enough to address many LSI issues such as those related to human induced climate change.

In terms of management of LSI through coordination of separate terrestrial and maritime spatial plans, it was felt that a strength of this approach lay in its recognition of the important differences between terrestrial and maritime spatial planning and that the approach allows more specialised plans to be prepared reflecting their distinctive economic, social, environmental, legal and political contexts. In addition, unlike ICM, it was noted that both MSP and terrestrial plans tend to be legally enforceable and therefore have greater potential to provide a clear legislative framework to address many LSI concerns if appropriate mechanisms for coordination between plans for the land and the sea can be found. However, it was acknowledged that such approaches by definition are not holistic and risks remain of the legislative fragmentation/ complexity, difficulties in communication, coordination and joined up implementation that lie at the heart of many ocean management problems today.

23 European MSP Platform, Maritime Spatial Planning: Addressing Land-Sea Interaction St. Julian's Malta, 15-16 June 2017 Conference Report (European Commission, Directorate General for Maritime Affairs and Fisheries 2017). 
More enthusiastic support was given to approaches which sought to manage LSI by extending terrestrial planning into marine areas. These were considered to be more holistic and potentially more coherent as overall control of planning lay under the authority of one body, meaning conflicts could be reduced and implementation is likely to be easier. Some went as far as suggesting that such arrangements were 'ideal' from an LSI planning point of view, not least in their potential ability to more readily engage with landward communities. However, others felt that there could be a danger of terrestrial dominance in such approaches and a risk of simply copying mistakes / approaches from the land and not developing new tools appropriate to the marine context. The dominance of economic agendas in determining planning priorities was an underlying concern here. It was also feared that many terrestrial planning authorities may not have sufficient data, experience or understanding to take aspects of the marine agenda reasonably into account. Again, the issue of scale both landward and seaward was raised with a concern that such arrangements may not be strategic enough to address key LSI concerns.

The conference discussions also considered the experience of various existing transnational coordination arrangements from an LSI management perspective and this again revealed a mixed picture. Interestingly, in all European sea basins, it was evident that transnational institutional and legislative arrangements are already established that can help member states with managing LSI. These range from institutions associated with international conventions to regional development programmes and projects, as well as mechanisms associated with the coordinated delivery of European Directives including the Marine Strategy Framework Directive, the Water Framework Directive and the Marine Spatial Planning Directive. In addition, in Europe it was evident that various other transnational fora also exist, ranging from the formal to the informal, that could play a role in helping to address LSI. However, it was noted that many of the transnational coordination arrangements were only partial in the coverage of LSI issues and/or land/sea responsibilities and that the scope for improved synergy and joined up action to better address LSI at a regional sea scale was great.

It is important to note that European experience discussed above is not necessarily representative of the wider global scene. However, it can perhaps provide a useful basis for considering future patterns of governance from an LSI and EA perspective and with this in mind a number of key messages are distilled which maybe of wider relevance. 
Firstly, as human pressures on the sea intensify and the need for sustainable management of marine resources is increasingly recognised, the ocean is becoming the focus of governance innovation informed to a significant degree by EA perspectives. The establishment of new systems of MSP is proving to be a particular source of this innovation as a result of efforts to integrate MSP into established governance structures and also address the challenges raised by LSI. In this way ocean planning and management are emerging as important drivers of change in 'territorial' governance more generally, creating new opportunities to move towards the overarching EA ambition of integrated management of land, water, and living resources. In so doing MSP related developments are not only challenging traditional divisions between governance of the land and sea, they are arguably also bringing environmental perspectives more to the fore as these are more central in legal frameworks related to the sea, than they are on the land. In this way ocean governance developments may provide the impetus to begin to embed Earth Systems understanding into global governance structures at all scales and in so doing help to promote conservation and sustainable use of ecosystem resources both in the sea and on the land. ${ }^{24}$

Secondly, European experience indicates that there is no 'one size fits all' solution to establishing governance arrangements that address LSI. It is clear that context matters and what is appropriate and deliverable in any situation will be influenced by variations in physical and human geography and will need to respond to different administrative and legislative histories and cultural norms and practices. Equally, it is evident that different governance approaches will have their own strengths and challenges from an LSI and an EA perspective and a combination of approaches is likely to be beneficial. The development of a nested or mixed governance architecture along these lines would of course be entirely consistent with EA understanding as reflected in EA principles 2 and 7.25

Finally, consideration of LSI and EA in the context of ocean governance highlights the value of an adaptive governance outlook which encourages: governance experimentation; opportunities for collaborative discussion and reflection; and ongoing governance adjustment in light of experience and changing understanding. With this in mind, it seems that public fora constructed to support 'territorial'/LSI and adaptive governance perspectives should be an important feature of future EA informed governance architecture

\footnotetext{
24 K Nash and others, 'Planetary boundaries for a blue planet' (2017) 1 Nature Ecology and Evolution 1625 .

25 M Mellett and others, 'Attainment of ecosystem based governance in European waters A State property rights regime approach for Ireland' (2011) 35 Marine Policy 559.
} 
and a key mechanism to extend ocean literacy and focus the development of a Blue Society. It is interesting therefore, given the global orientation of much ocean governance and EA debate so far, to recognise that local level ICM initiatives might provide valuable sources of inspiration about the form that such fora might take, how the concept might be applied at different scales, and also of the challenges inherent in their development, operation and sustainability over time.

\section{Bibliography}

\section{Books}

Chang YT, Ocean Governance a Way Forward (Springer, 2012).

Cicin-Sain B and others, Integrated coastal and ocean management: concepts and practices (Island Press 1998).

Kidd S, Plater A and Frid C, The Ecosystem Approach to Marine Planning and Management (Routledge 2011).

Pelling M and Blackburn S, Megacities and the coast: risk, resilience and transformation (Routledge 2014).

\section{Official Publications}

Ærtebjerg G, Andersen JH and Hansen OS (eds), Nutrients and Eutrophication in Danish Marine Waters. A Challenge for Science and Management (Danish National Environmental Research Institute 2003).

Ecorys, Blue Growth Scenarios and drivers for Sustainable Growth from the Oceans, Seas and Coasts: Final Report (European Commission, Directorate General for Maritime Affairs and Fisheries 2012).

Ehler C, Final Report of 2nd International Conference on Marine/Maritime Spatial Planning (IOC-UNESCO and EC-DG Mare 2018).

European Marine Board and CoExploration Limited, Sea Change Ocean Literacy Fact Sheet (European Marine Board and CoExploration, Limited, no date).

European MsP Platform, Maritime Spatial Planning: Addressing Land-Sea Interaction St. Julian's Malta, 15-16 June 2017 Conference Report (European Commission, Directorate General for Maritime Affairs and Fisheries 2017).

Intergovernmental Oceanographic Commission (of Unesco), Outcomes of the UN SDG 14 conference (5-9 June 2017): Information Document (Intergovernmental Oceanographic Commission, Paris, 2017).

Ocean Literacy Campaign, Ocean Literacy: The Essential Principles and Fundamental Concepts of Ocean Sciences for Learners of All Ages Version 2, a brochure resulting 
from the 2-week On-Line Workshop on Ocean Literacy through Science Standards (National Oceanic and Atmospheric Administration, USA, 2013).

Ruprecht Consult and The International Ocean Institute, Evaluation of Integrated Coastal Zone Management in Europe: Final Report (European Commission 2006).

Societe d'exploitation Du Centre National de la Mer, Sea For Society: Final Report Summary (European Commission, Community Research and Information Development Service, 2013).

Swedish Environmental Protection Agency, What's in the sea for me? - Ecosystem Services Provided by the Baltic Sea and Skagerrak (Swedish Environmental Protection Agency 2009).

United Nations Environment Programme, Marine and coastal ecosystems and human wellbeing: A synthesis report based on the findings of the Millennium Ecosystem Assessment (UNEP 2006).

United Nations World, Population Prospects: The 2017 Revision (United Nations 2017).

University of Liverpool, ESTaDOR European Seas Territorial Development Opportunities and Risks: Executive Summary (European Spatial Planning Observation Network 2013).

University of Liverpool, Marine Proofing for Good Environmental Status of the Sea: Good Practice Guidelines for Terrestrial Planning (Celtic Seas Partnership 2016).

\section{Journal Articles}

Mellett M, Curtin C, Hennessey T, and O'Hagan AM, 'Attainment of ecosystem based governance in European waters - A State property rights regime approach for Ireland' (2011) 35 Marine Policy 559.

Nash NL, Cvitanovic C, Fulton EA, Halpern BS, Milner-Gulland EJ, Watson RA and Blanchard J, 'Planetary boundaries for a blue planet' (2017) 1 Nature Ecology and Evolution 1625.

Osherenko G, 'New Discourses on Ocean Governance: Understanding Property Rights and the Public Trust' (2006) 21 Journal of Environmental Law and Litigation 317.

Schoedinger S, Tran LU and Whitley L, 'From the Principles to the Scope and Sequence: A brief history of the ocean literacy campaign' (2010) Special Report 3 The Journal of Marine Education.

Schrijver N, 'Managing the global commons: common good or common sink?' (2016) 37:7 Third World Quarterly 1252.

\section{Other Sources}

СвD Conference of the Parties, $2000 \mathrm{~V} / 6$. 